\title{
RETROSPECTIVE STUDY ON THE ITERATIVE METHODS OF ARCHITECTURAL VISUALIZATION FROM THE NEOLITHIC TO THE DIGITAL BUILDING INFORMATION MODEL
}

\author{
MATTHIAS STANGE \\ HafenCity University Hamburg, Germany
}

\begin{abstract}
The current application of building information modelling (BIM) is supposed to be a promising design methodology and plays an essential role in visualizing the architectural process from the early design phase through planning and construction up to building usage and recycling. The application of BIM and its associated processes are seen as key to increasing productivity in the architecture, engineering and construction (AEC) industries. With the help of BIM, all building information is available in real time to all stakeholders involved throughout the entire lifecycle. However, there is a large research gap on the developmental steps of architectural visualization from the beginnings of civilization in the Neolithic through the outstanding discoveries of the Renaissance to the digital building information model we use today. In particular, in response to the questions: What fundamental developments in architectural visualisation have made the currently used building information model possible, and what are the prospects? With the help of an extensive literature review, this study examines the developmental stages of architectural practice and architectural visualisation, as well as their communicative achievements and culture-creating or culture-changing effects. The analysis focuses on the triggers of significant developments, their importance for subsequent methods and the transmission of knowledge across epochs. In particular, with regard to the main barriers to the implementation and use of BIM, which are still present despite the fact that BIM has been on the market since the 1980s.

Keywords: architecture engineering construction (AEC) process, visualization, development stages, knowledge transfer, building information modelling.
\end{abstract}

\section{INTRODUCTION}

Architectural visualisation has been practised for as long as there have been buildings. Visualisation generally refers to the process of translating abstract data and relationships that are difficult to formulate linguistically or logically into a graphical, visually comprehensible form. During the design phase, architectural visualisation initially serves the aesthetic verification and visualisation of the developed idea. During further design development, visualization helps to represent the geometric, structural and semantic information of the future building for construction and use, including all spatial dimensions, materials, key figures and technical characteristics. Builders have always been interested in how their building will look and operate before it is built. Only the prior visualization of the structures allows timely influence on the further development of the buildings in terms of cost, time and quality. In this respect, architectural visualization has always represented an early (and only) basis for decision-making in the construction process. Towards the end of the 19th century, the traditional, analogue methods of representation were replaced by computer-aided, digital methods of representation. However, these fundamental changes in the production of space and new forms of representation have not emerged incoherently. Looking at the history in terms of the media and methods of architectural visualisation, it becomes clear that this development was an iterative process that successively had an impact on the production of space and the theory of space. This study focuses on the basic research of architectural 
practice from the beginnings of civilization in the Neolithic, through the outstanding discoveries of the Renaissance, to the digital three-dimensional building information model we use today. The triggers of further developments, their significance for subsequent techniques, and the epoch-spanning transmission of knowledge are of particular interest, as well as their communicative achievements and their culture-creating and culture-changing impact. The analyses focus geographically on the two regions: Ancient Orient and Egypt in pre-Antique times as well as Europe in antiquity (Greece and Roman Empire), in the Middle Ages mainly France and Germany, in the modern times and modernity mainly Italy and partly north of the Alps. The cultural areas of China, Southeast Asia, Africa, India, the Islamic world, the advanced civilizations of South America, and the European-influenced America and Australia of the early modern period were not included. The division by epochs and cultural areas was chosen because building knowledge has historically consistently provided specific solutions to tasks that were fundamental to the natural and social needs of a particular society or culture. However, the knowledge of the media and methods of architectural visualization underlying the great building achievements of the past has hardly been made the central subject of cross-epochal investigations.

\section{THE ANTIQUITY}

Antiquity is a term used in the historical sciences and, for the Mediterranean and Near Eastern civilizations, covers the period from the beginning of the Neolithic (around $5600 \mathrm{BC}$ ) to the beginning of the Middle Ages (around 600 AD). Spatially, antiquity refers to the Mediterranean region and the Near East and also includes classical antiquity both temporally (depending on the delimitation, from 1700 or $800 \mathrm{BC}$ to about $600 \mathrm{AD}$ ) and spatially (Ancient Greece and the Roman Empire). At the beginning of antiquity there is the formation of the ancient oriental civilizations of the Near East: Mesopotamia, Persia, Levant, Asia Minor and Egypt. Antiquity ends with the downfall of the Roman Empire during the migration of peoples around $375 \mathrm{AD}$ until the invasion of the Lombard's in Italy around $568 \mathrm{AD}$.

\subsection{Ancient Oriental civilizations}

Some of the most significant changes in human history took place during the Neolithic period. While in the Old Stone Age (Palaeolithic) people made their living by hunting animals and gathering plants, around $4000 \mathrm{BC}$ agriculture and animal husbandry increasingly prevailed as the basis of the economy. The change in subsistence strategy, from food appropriation to food production, is considered an essential feature of Neolithic cultures and established for the first time the need for a sedentary way of life in permanent settlements (instead of caves as before) and thus to produce buildings. According to Kurapkat [1] the Australian-British archaeologist and archaeological theorist Vere Gordon Childe (18921957) coined the term "Neolithic Revolution" to describe these pivotal changes. In the Neolithic period, the decisions about the size and orientation of the building and its layout, which were made mentally before the actual start of construction, already constituted the building plan. The use of the natural measures of length, foot and cubit, made it possible to transfer an imagined plan defined by proportions directly to the building ground, for example by laying out the ground plan with stones or by staking out alignment lines. Later, these imagined plans, defined by proportions, were applied to small wax tablets, or carved into clay tablets to be made available for construction. Renn and Valleriani [2] report that the invention of cuneiform writing in Mesopotamia, texts initially also served as a tool for construction planning, since most ancient Near Eastern buildings were based on a canonical construction method that both builders and workers could imagine without construction drawings. 
Fauerbach [3] reports that plans on papyrus, with graphic elements and explanatory inscriptions as well as isolated measurements, have survived from ancient Egypt for the first time. Likewise, detailed models of clay, for example of door jambs and column capitals, have survived.

\subsection{Ancient Greece}

The outstanding achievements of ancient Greece in the fields of poetry and philosophy, as well as the knowledge gained in the fields of mathematics, geometry and optics, laid the foundation for the cultural development of the Occident. In architecture, the Doric temple was developed to maturity and planning was applied beyond the individual building for the first time, such as urban planning as an overall architectural work. The architectural drawing occupies a special position in ancient Greece. On the one hand, as a medium in which the actual design work took place in order to develop determining proportions in the floor plan and elevation through geometric construction. On the other hand, as a medium to visualize the design idea to the client and the executing craftsmen. The most important source for the analysis of ancient design procedures are the buildings themselves. Of particular importance in this context are the building drawings, which have survived in the form of incised drawings on a few building elements or walls. With regard to their significance for Greek architects, a distinction must first be made between the function of these drawings. On the one hand, drawings can be the medium in which the actual design work took place, in order to develop determining proportions in the ground plan and elevation through geometric construction (e.g., compass strokes, triangular constructions or golden section). On the other hand, drawings can be the medium to visualize the design idea to the client and the executing craftsmen. In addition to the drawings, the inscriptions of the buildings also provide important clues to the working methods of the Greek architects. Osthues [4] interprets these inscriptions as a work outline representing the profile from which the stonemasons could take the individual measurements with the chisel. For the Hellenistic period, it is documented that inscriptions not only designated the outline of the work for the executing stonemason, but also a construction drawing for the purpose of form-finding by the architect.

\subsection{Roman Empire}

In Roman architecture, the Greek model had a striking effect, especially in architectural details and decoration. The Romans adopted the Greek column orders and temple forms. Independent achievements lay in the development of new types of buildings, such as forums, basilicas, thermae, amphitheatres, podium temples and triumphal arches. But also, the typical Roman developments of road construction, viaducts and aqueducts. Roman architecture made great strides in floor plan and room design. The principles of symmetry and axiality prevailed and were equally effective in representative buildings, monumental plazas and sacred buildings. The Romans also made an important contribution to urban architecture. The development of axiality improved spatial organization, which was unmistakably expressed in the system of the Via Appia (long-distance roads) and aqueducts for the transport of water. Beginning in the Augustan period (30 BC to AD 14), Greek Hellenistic architecture in much of the Roman Empire was increasingly absorbed into established Roman architecture.

To illustrate the way in which a Roman architect presented his ideas to a client, reference is made to the Roman architect Vitruvius (c. $80 \mathrm{BC}$ to $15 \mathrm{BC}$ ). Vitruvius requires the architect to be able to represent his designs graphically and lists the three types of architectural drawing representation: Orthographia, Ichnographia, and Scaenographia (elevation, floor plan, and 
perspective view). The Greek terms used by Vitruvius indicate that the design of buildings from drawings was first developed by Greek architects. It is probably a development from the time of Hellenism, because for the classical period almost all researchers now assume that the designs were worked out using other methods. From Vitruvius's point of view, the drawing representation of the design idea is the core competence of the architect. He describes this clearly in a passage from his sixth book:

"[...] that if a building is successful in terms of craftsmanship, it is to be attributed to the craftsman in charge of the construction. That if the building is splendidly equipped, it is to be attributed to the financial strength of the builder. And if the building, however, turns out gracefully, it is the glory of the architect."

Vitruvius supports this statement in the same place:

"[...] that only the architect has the ability to form an accurate and concrete idea of the building even before the building takes shape in reality, so that he can reliably assess design decisions in advance. Therefore, the architect must present his client with an idea of the proposed building design, and sketches and drawings serve this purpose."

The design of buildings on the basis of proportions can be traced not only in the designs of Vitruvius, but also in later measurements of Roman buildings. Mark Wilson Jones (2000), in his comprehensive study of the design practice of Roman architects, concludes that certain proportions would even have established themselves as standard designs. Consequently, the main dimensions of many buildings were established in simple multiples of five, ten or twelve feet. It is also certain that many detailed forms of building elements were constructed geometrically by drawing. However, detailed forms were also constructed with the help of so-called mixed forms, through computational and geometric approach.

\subsection{Transmission of the ancient building knowledge}

Wesenberg [5] reports that in ancient times, there was a vast literature on Greek architecture, however, but all these writings are lost. In the introduction to the seventh of his ten books on architecture, Vitruvius notes that there are writings about individual Greek buildings whose authors he mentions by name. Among others, he names Theodoros as author of a writing about the Hera temple of Samos, Pytheos as author of a writing about the Athena temple of Priene, and Chersiphron and Metagenes as authors of a writing about the Artemision of Ephesus. Among the Romans, architectural writings, with the exception of Vitruvius' De architectura libri decem, were hardly known. However, we know through Vitruvius that there were individual texts on architectural topics before his work, but not an overall presentation. It is also known that the Roman polymath Marcus Terentius Varro (116 BC to 27 BC) - without being an architect himself - also wrote a book on architecture for his Disciplinarum libri IX (Nine Books on the Subjects), which is, however, lost. Only one architectural writing, also lost, is known from later times, that of the Greek writer Apollodor of Athens (c. $145 \mathrm{BC}$ to $120 \mathrm{BC}$ ) about the construction of the so-called Trajan's Bridge. 


\section{THE MIDDLE AGES}

In European history, the Middle Ages refers to the period between the end of antiquity and the beginning of the modern era. The European Middle Ages extend from the end of the Migration Period in 568 to the beginning of the Early Modern Period around the middle of the 14th century. Spatially, the following section mainly refers to the European Middle Ages in France and Germany. From a humanistic point of view, the Middle Ages were an aetas obscura (dark age) in which the social, technological and cultural level of development of Greco-Roman antiquity was completely lost. The understanding of reality in the Middle Ages was not focused on the sensually perceptible world, but predominantly on unreal and twodimensional world views. For example, the understanding of the earth as a disk over which God rules in heaven, which was spread by the church. In the Middle Ages, church building was the most essential building task. The initiative for the construction of a building came exclusively from a theologically educated builder, who was also the source of ideas. Architecture was considered a secret science in the Middle Ages and was banned. The technical construction was led by master craftsmen who had collected building knowledge passed down to them during their travels and used it in the new buildings.

\subsection{The medieval drawing}

The shape of medieval buildings initially existed only in the imagination of the clerical builders, and the buildings were designed opus in mente conceptum (in the mind). The ground plan was then drawn and marked out by the master craftsmen directly on the building site, similar to the procedure in the Neolithic period. The lack of construction plans requires a precise verbal list of the required services by the master craftsmen. According to Binding [6] small sketches on wax tablets could capture the image of the planned building in the mind. Complete floor plans have survived as coloured pen drawings in manuscripts only since the middle of the 9th century. The St. Gallen monastery plan also belongs in this context (Fig. 1).

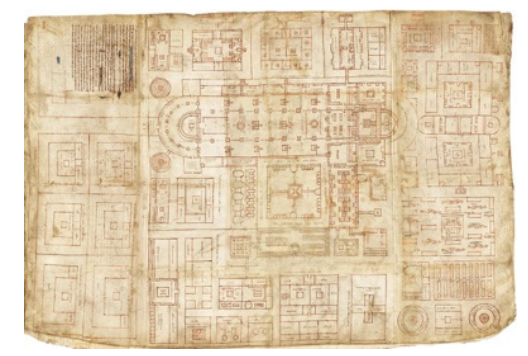

Figure 1: St. Gallen monastery plan.

View drawings have also been known in handwritten form as illustrations since the turn of the millennium, for example in the Psychomachia of the Christian poet Prudentius in the Vatican (around 1000), in the Hillinus Codex of Cologne Cathedral (around 1025) or the water supply plan of the Canterbury monastery (around 1160). Around 1260, the oldest drawing was made for a partial elevation of the west facade of the Strasbourg cathedral, influenced by the facades of the Paris cathedral. Drawings of other building sites also date from the last quarter of the 13th century. This is also the case with the oldest preserved drawing of the west facade of Cologne Cathedral from 1248, presumably drawn by Master 
Arnold. The plan drawn on parchment is one of seven surviving medieval architectural drawings of Cologne Cathedral. The drawing of the west facade of Cologne Cathedral stands out unmistakably from the drawings of the late 13th century due to its size of 4.05 metres and its precision. The knowledge of the Greco-Roman art of measurement was never lost in the Middle Ages. Geometry provided the basic knowledge for measuring the building and in this way made it possible to realise the form. The first building plans to scale were made in the Middle Ages. Information about the tasks of a High Medieval craftsman can also be found in the only surviving book on the building trade from the Middle Ages, whose drawings were made by Villard de Honnecourt (c. 1200-1250) on his travels, partly from reality and partly from pictures. His sketches provide valuable information on the planning techniques of the time. Especially for Reims Cathedral and for the development of planning procedures in the High Gothic period is of utmost importance. He depicted the cathedral of Reim on six sheets with interior and exterior views as well as detailed drawings (Fig. 2). The plans do not serve as real building plans but represent diagrams describing the form concepts. The views of Reims Cathedral are presented in a curious folding view that does not require spatial foreshortening. However, the laws of perspective, which were known to the Romans, were not to be rediscovered until the Renaissance. The frequently expressed view that he was more of a theorist is rather unlikely in view of the multitude of details in his pattern book.

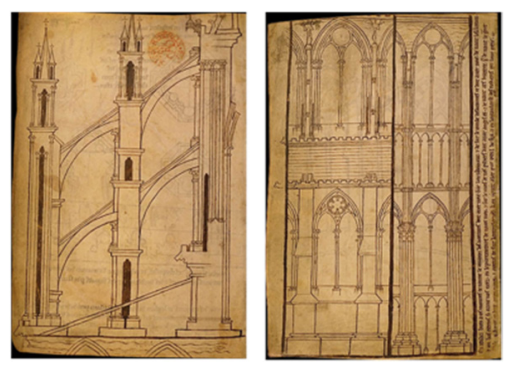

Figure 2: Cathedral Reims, Honnecourt.

\subsection{Transmission of the medieval building knowledge}

Hardly anything is known about building knowledge and its transmission for the early and high Middle Ages. The master craftsmen could neither read nor write, they were so-called illitteratus (did not know Latin). They were therefore unable to access important textbooks such as De architectura libri decem by Vitruvius or Geometria by Boethius. In analogy to God's creatorship, the medieval builders and master craftsmen shaped every item as a form according to the same law by which God created the world: Omnia mensura et numero et pondere disposuisti (all things are ordered by measure, number and weight). Of particular interest were the numbers, especially the geometric interpretation of the numbers. Geometry thus provides the basic knowledge for measuring buildings and in this way enables the spatial realisation of the form. Innovative changes in the planning and construction process of buildings appeared in the first half of the 13th century, such as building plans or templates and, last but not least, the possibility of prefabricating the templates over the winter months in a so-called "Bauhütte". The pattern book of Villard de Honnecourt illustrates this change. Nevertheless, the design process, the knowledge of materials and construction techniques as well as the organisation of logistical construction processes were still based on oral instructions and experience during the building process at that time. A normative 
architectural theory in the sense of antiquity or later the Renaissance, as exemplified by Alberti, Filarete or Serlio, did not exist in the Middle Ages.

\section{THE MODERN ERA}

In European history, the modern era refers to the period between the late Middle Ages, around the middle of the 14th, and the transition from the 18th to the 19th century. In European history, the modern era refers to the period between the late Middle Ages around the middle of the 14th century and the transition from the 18th to the 19th century. The early modern period is considered to be the beginning of a new era in which a new image of human spread throughout Europe. The focus was on the self-determination of humans and their abilities. The developments of the modern era can first be identified in Italy, where it began as early as the 14th century and reached its cultural heyday in Florence in the following 15th century. From there it spread throughout Europe until the beginning of the 16th century. The predominant artistic and architectural styles are Renaissance and Baroque.

With the end of the 14th century, the ancient building typologies, proportions, and structural systems became the model for the formal language of the buildings of the early modern period. With the paradigm of antiquity, the figure of the architect became recognized again, the cultural man trained theoretically and, in many subjects as Vitruvius describes him. Leon Battista Alberti is more pragmatic on this point and sees the qualification of the architect not only in the perfect ability in many subjects, but also emphasizes the importance of drawing and model making as well as knowledge of painting and mathematics. In 1563, under the leadership of Giorgio Vasari and Vincenzo Borghini, the Accademia et Compagnia dell'Arte del Disegno (Academy of Design) became founded. The Italian term Disegno (to draw) is a fundamental concept in the Renaissance art theory, interpreting drawings as both an artistic idea and an intellectual concept. Schlimme et al. [7] report that during the Renaissance, painters and sculptors made up a substantial proportion of Italian architects, such as the sculptors Filippo Brunelleschi, Antonio di Pietro Averlino (called Filarete) and Gian Lorenzo Bernini, or the painters Donato Bramante and Giorgio Vasari. Architecture encompassed increasingly fields of activity that could clearly belong to the arts of Disegno, primarily the actual architectural design. But there were also activities from which academics wanted to clearly distinguish themselves, such as construction. The visible result of the architect's work was more and more the creative design idea illustrated in drawings, which was then realized in a second separate step.

\subsection{The discovery of perspective}

Even in ancient times, people had a concept of perspective. The ancient concept of perception through vision is based on the assumption of the Greek mathematician Euclid (c. 365 to 300 $\mathrm{BC}$ ): vision occurs through visual rays that connect the eye to the object being viewed by the shortest route. In the Middle Ages, the beginnings of perspective representation fell into oblivion. During the Renaissance, perspective was rediscovered and promoted by patrons in Florence and other Italian cities. The Florentine sculptor Filippo Brunelleschi (1377-1447) is considered the discoverer of perspective. After a series of experiments at the beginning of the 15th century, Brunelleschi developed the central perspective projection. Around 1420, Brunelleschi demonstrated central perspective in an experiment in the cathedral square of the Baptistery of Santa Maria del Fiore in Florence by creating a lifelike image of the building using a mirror apparatus and a panel painting. Brunelleschi's practical experiments were theoretically substantiated by Leon Battista Alberti (1404-1474) in his painting treatise Delle pittura (The Painting) from 1435 and written down for the first time on the basis of his 
scientific investigations into vanishing points and horizons. Alberti abbreviates Brunelleschi's perspective method for the practical use of painters. According to Alberti's principles, the optical image is created by rays of vision in the form of a cross-section of a visual pyramid, whereby the size and shape of the objects as they appear in the optical image are determined by the relative position of the rays of vision. In 15th century Italian art, the innovations in painting and architecture seem to support each other in a remarkable way. The fact that architecture and painting entered a particularly close relationship in the early Renaissance is exemplified by Alberti's painting treatise Delle pittura. In it, Alberti speaks conspicuously often of architecture. To explain the perspective construction of the pictorial space, Alberti refers, for example, to a regularly structured floor (the so-called pavimento), which he constructs with the help of the vanishing point and distance method (Fig. 3).

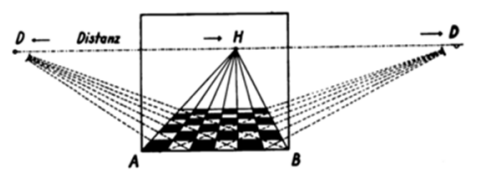

Figure 3: Albertis's "pavimento".

What is indicated in Alberti's treatises can also be observed in Italian painting of the Quattrocento. Architectural forms and structures are fundamental to a new form of representation that emerged particularly during the establishment of perspective and made a decisive contribution to Renaissance painting. As in the case of the Italian painter and architect Raffaello Sanzio da Urbino (1483-1520) in his work "School of Athens" (Fig. 4). The painting is a fresco that Raphael made for Pope Julius II in the Stanza della Segnature of the Vatican. This painting, as well as numerous others from Renaissance painting, is an example of central perspective. In addition to the lines running to the central vanishing point, it is easy to see how the foreshortening of similar objects intensifies the effect. Especially when the columns behind relate to vanishing lines.

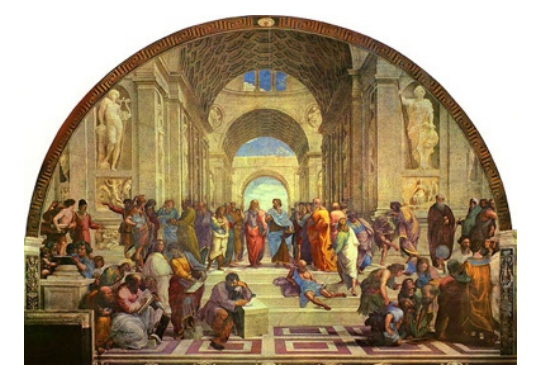

Figure 4: School of Athens, Raffaelo.

In the 15th century, Alberti demanded the use of orthogonal projection. In contrast to the painter's picture, which attempts to represent spatiality through perspective, the architect's ground plans and views represent spatiality in scaled reduction and true angles. Alberti thus detaches perspective from Vitruvius' Ichnographia, Orthographia and Scaenographia, criticising the conflation between orthogonal projection and perspective. By the beginning of 
the 16th century, orthogonal projection was then a firmly established planning tool, as for example with the Italian architect and fortress builder Antonio da Sangallo the Younger (1484-1546). The role of Brunelleschi has only been emphasised in retrospect, who contributed significantly to the perfection of representational techniques with his experiments in perspective in front of the Florentine Baptistery. The decisive novelty of linear perspective was not to depict existing objects, but to represent invented objects and spaces. The mastery of perspective, but above all the perfection of orthogonal projection, promoted the development and diversity of use of architectural drawing.

\subsection{The illusionist appearance in the Baroque}

As the 17th century progressed, an increased artistic ambition in architectural representation became more and more apparent. Coloured washed surfaces in the presentation drawings clarified materials, construction phases or cut surfaces. An appealing design of the drawings was intended to win over the clients for the design. Gerber [8] reports that the term "appetite sketch" is documented from the Baroque period. Baroque is generally associated with the idea of illusionistic appearance in contrast to the representational reality that dominated the Renaissance. According to Wölfflin (1915), the Renaissance still adheres to real substance and conveys a "tactile image". The Baroque, on the other hand, creates a pure "visual image" that is rooted only in the eye and addresses only the eye to create an optical effect. The illusionistic appearance of the Baroque is always associated with Gian Lorenzo Bernini (1598-1680), one of the most important Italian sculptors and architects of the Baroque. Two examples are demonstrable evidence that Bernini saw the effect of his architecture as a component in its own right. One example concerns the decoration of St Peter's Church in Rome. In his sketch, Bernini records how one can see the Cathedra Petri (the Pope's chair) in the choir through the canopy above the high altar. The other example concerns his design of St Peter's Square in Rome, where he was confronted with the problem that the facade of St Peter's appeared too flat and broad (Fig. 5).

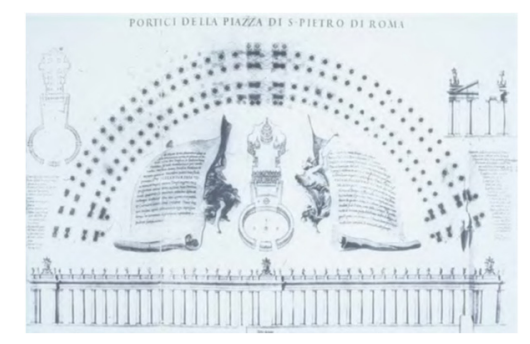

Figure 5: St. Peter's Square Rome, Bernini.

For this reason, he placed colonnades around the square and tried to visually elevate the facade by contrasting the lower members. With the help of this optical illusion, Bernini succeeded in giving the facade of St Peter's a more sublime visual effect. Seen from a distance, the facade of St Peter's rises majestically above the colonnaded square and is crowned by the dome of St Peter's Basilica. Colonnades were already known in ancient Greece and Rome and served to enclose public squares. For example, the Agora of Athens or the colonnaded streets of Roman city foundations. 


\subsection{Transmission of modern era building knowledge}

In the early modern era, building knowledge was recorded in tracts, books, manuscripts or engraved publications. The architectural treatises and annotated translations of Vitruvius' writings made it possible to deal with the questions of building in a way that had not been known before. The architectural treatises of the Renaissance, such as those by Leon Battista Alberti (1485) or Vincenzo Scamozzi (1615), but also most of the annotated editions of Vitruvius, presented the basic principles of architecture and were intended to convey the abstract idea of architecture and the cultural as well as practical value of architecture. Quality concepts and design principles of antiquity is the central theme of these treatises. Other tracts of the Renaissance, such as that of Sebastiano Serlio (1537), were to be regarded as sets of rules and reports of experience from planning and building practice. In the 17th century, the tendency to publish buildings in architectural tracts increased. This was also the case with Guarino Guarini (1624-1683), one of the most important architects of the late Baroque or Sicilian Baroque, in his tract Architettura Civile (Civil Architecture), published posthumously in 1686. His writings Placita Philosophica (1665), Euclides Adauctus (1671) and Architettura Civile (1686) play a pioneering role in descriptive geometry. In the 17th and early 18th centuries, modern Roman architectural culture in particular was published, for example the publications of Valerianus Regnartius (1650) or the Nuovo Teatro delle Fabbriche edited by Giovanni Giacomo de Rossi (1665) and engraved by Giovanni Battista Falda (1699).

\section{THE MODERN AGE}

In the Querelle des Anciens et des Modernes (1687), an intellectual-historical debate in France at the turn of the 17th and 18th centuries, modernity was still the antithesis of antiquity. The question was to what extent antiquity can still be the model for contemporary art. In the history of architecture, modernism refers to an epoch that cannot be easily defined. In the classification schemes of architectural history, a distinction is made between Early Modernism, Classical Modernism and Postmodernism, whereby a multitude of styles developed within these boundaries, sometimes simultaneously. The beginning of modernism saw the development of Art Nouveau (c. 1880-1914), which was characterised by decorative ornamentation and the abandonment of symmetries. Classical Modernism (around 1920 until today) initially begins with minimalist and functional tendencies. Afterwards, this style became more and more prevalent. In architecture, this refers in particular to those purposedriven works that later became famous as Bauhaus style or Bauhaus architecture. Postmodernism generally refers to the expression of Western society, art and culture after modernity.

\subsection{The expanded concept of architecture in the early 20th century}

Architecture and space on the one hand, and movement and time on the other, were not discussed in a single context until well into the 19th century. Yet the movement of people in architectural space was a central theme of architectural designs in this period. According to Noell [9] the progress of industrialisation and the associated technical possibilities arose the question of a changed relationship between space and time in the 19th century. In 1904, the Dutch physicist Hendrik Antoon Lorentz (1853-1928) replaced the previous understanding of time with that of a time dependent on the state of motion for the first time with the socalled "Lorentz transformation". The German physicist Albert Einstein (1879-1955) published his work "Electrodynamics of Moving Bodies" in 1905 and several books on his 
special and general theory of relativity in the following years. Around 1907, the German mathematician and physicist Hermann Minkowski (1864-1909) realised that the work of Lorentz and Einstein could be understood in a (Non-)Euclidean space. Minkowski [10] argued that space and time are connected in a four-dimensional space-time continuum. Almost all painters, sculptors and architects of the early 20th century who sought an artistic redefinition of space and time referred to these three scientists in deriving or justifying their positions.

The Dutch painter and architect Theo van Doesburg (1883-1931) attempted to develop a new definition of spatiotemporal architecture around 1919. In 1923, together with the Dutch architect Cornelius van Eesteren (1897-1988), he recognised that axonometry, as opposed to perspective, was no longer fixed to the viewer's point of view and a vanishing point. Axonometry enabled a separation from the individual viewer and thus from a fixed position in space. Axonometry thus deviates from the spatial representation of perspective, which is considered finite, since it allows for an infinite and seemingly universally valid representation of space. Moreover, it opens up the possibility of all-round observation, which includes a rotation in space. Van Doesburg argued that the new architecture (or rather the representational method of axonometry) made front and back, and possibly top and bottom, equal. Axonometry thus laid the foundation for today's digital architectural visualisations.

\subsection{The computer-based production of space in the late 20th century}

After the invention of the world's first fully automatic, programmable computer by Konrad Zuse in 1941, the first geometric formalisations in the 1950s and the first drawing approaches in the 1960s, the so-called computer-aided design (CAD) entered the planning practice of architects and civil engineers in 1985. Moelle [11] refers to the introduction of CAD as the first digital revolution in construction and then later the shift from two-dimensional CAD to $3 \mathrm{D}$ modelling as the second digital revolution in construction. In the 20th century, the computer became the dominant tool in contemporary architectural production. The computer is still used today for the production of architectural drawings. In addition to the possibility of a three-dimensional visualisation of the design idea, through which extended spatial ideas can be gained, the benefit of the computer is seen above all in the acceleration of the entire planning and building process.

Increasingly, architects discovered the possibility of using modern computer technology to deviate from basic geometric forms and bring about a change in conventional architectural forms. In the 1990s, the computer became a suitable instrument for the precise planning and construction of such free forms. Until then, computer-aided design systems had aimed to produce a coherent order in response to complex conditions. Peter Eisenman, however, introduced the computer into architectural production in order to reject holistic structures of order, to decouple form from function. For him, the computer was an effective instrument for "overcoming the metaphysics of architecture" - as he calls it. Frank O. Gehry, on the other hand, is an outstanding representative of those architects who carry out and monitor spatial complexity with the computer, but do not create it with it. His buildings of the late 1990s were often misunderstood as so-called "computer architecture" due to their sleek appearance and computer-based production.

While Gehry, who designed in analogue and built digitally, turned to the computer in an application-oriented way and only used it when it came to the detailed planning implementation of his designs, Peter Eisenman already used the computer as a conceptual design medium in the form-finding process. Characteristic of his design process was that the architect triggered the process of form formation and set in motion an automatism behind 
which he (the architect) seemingly disappeared. With the use of axonometry as a method of representation, Eisenman followed the pioneers of modernism, such as van Doesburg. Eisenman used the visual properties of axonometry to express his idea of "a-perspectival" and "disorganised" space without a preferred direction. Höfler [12] reports that one of the main advantages of axonometry is that, unlike perspective, it provides a geometrically more exact view of the object, as it conveys measurable relationships of lines, surfaces, and bodies.

\subsection{The digital building information model in the 21 st century}

The digital building information model in the 21 st century is based on the fundamental idea of product modelling to abstract and describe reality. An integrated product model contains all relevant product characteristics that arise in the individual life cycle phases of the product. The theoretical roots of product modelling can be seen in the conceptual modelling of database applications on the one hand and in object orientation on the other. An integrated product model contains all relevant product characteristics that arise in the individual life cycle phases of the product. Junge [13] describes product models as a structured digital representation of information of manmade objects, with the main purpose of a computeraided processing of this information throughout the life cycle of the represented object. The basis for this is a uniform, general, cross-lifecycle and redundancy-free basic structure. Wender [14] reports that product models in construction are based on an object-oriented modelled conceptual scheme that describes the data required across the life cycle in its entirety in a structured way. With the succinct words "Begin with the End in Mind", Charles E. Mies (member of the Autodesk AEC Business Development Team) made it clear that the feasibility and ideal use of the building should be the top priority right at the beginning of every construction project. Building information modelling (BIM) seems to be the key to virtually mapping multidimensional problems across disciplines and solving them across the life cycle. Mies [15] argues that the more information contained in this digital image of the building, the greater the added value for the entire project.

\section{CONCLUSION}

From the first civilizations over 6000 years ago to today's digital building information model, the visual representation of a proposed structure has been formed by ground-breaking social and technological developments. The outstanding discoveries of ancient Greece in the fields of mathematics, geometry and optics laid the foundation for the development of perspective representation in the early modern period. These changed the perception and representation of architecture and had a significant influence on the magnificent pictorial art of the "Quattrocento". As a result of the advancing industrialisation in the modern age and the associated technical possibilities, the question of a changed understanding of space and time arose at the beginning of the 20th century. Inspired by this, Theo van Doesburg and Cornelius van Eesteren developed a new "spatiotemporal" architecture around 1919 and recognised that axonometry, in contrast to perspective, enables detachment from the individual viewer and thus from a fixed position in space. Axonometry, in contrast to finite perspective, enables an infinite and seemingly universal representation of space as well as its all-round observation. Axonometry thus laid the technological foundation for the later computer-assisted architectural representation in an infinite three-dimensional space, the so-called Computer Aided Design (CAD). For the first time in architectural history, architectural objects could be modelled, visualised and, if necessary, modified in an active three-dimensional space. The possibility of object-based modelling through three-dimensional CAD forms the basis for today's building information modelling (BIM). With the help of BIM, specific attributes 
(properties) and methods (functions) can be assigned to each of the architectural objects in the model. This information is collected centrally in a database and is thus accessible to everyone involved in real time. BIM, whose origins lie in axonometry, makes it possible for the first time in the history of architectural representation to make the necessary information about a building available to all stakeholders in real time throughout the entire life cycle.

\section{REFERENCES}

[1] Kurapkat, D., Bauwissen im Neolithikum Vorderasiens. Wissensgeschichte der Architektur. Band I: Vom Neolithikum bis zum Alten Orient, eds J. Renn, W. Osthues \& H. Schlimme, Edition Open Access: Berlin, pp. 57-127, 2014.

[2] Renn, J. \& Valleriani, M., Elemente einer Wissensgeschichte der Architektur. Wissensgeschichte der Architektur. Band I: Vom Neolithikum bis zum alten Orient, eds J. Renn, W. Osthues \& H. Schlimme, Edition Open Access: Berlin, p. 26, 2014.

[3] Fauerbach, U., Bauwissen im alten Ägypten. Wissensgeschichte der Architektur. Band II: Vom alten Ägypten bis zum antiken Rom, eds J. Renn \& W. Osthues, Edition Open Access: Berlin, pp. 7-124, 2014.

[4] Osthues, W., Bauwissen im antiken Griechenland. Wissensgeschichte der Architektur. Band II: Vom alten ä̈gypten bis zum antiken Rom, eds J. Renn, W. Osthues \& H. Schlimme, Edition Open Access: Berlin, pp. 127-261, 2014.

[5] Wesenberg, B., Zu den Schriften der griechischen Architekten. Bauplanung und Bautheorie der Antike. Wasmuth: Berlin, 1984.

[6] Binding, G., Architectus, Magister operis, Wercmeistere: Baumeister oder Bauverwalter im Mittelalter. Mittellateinisches Jahrbuch, 34, pp. 7-28, 1999.

[7] Schlimme, H., Holste, D. \& Niebaum, J., Bauwissen im Italien der Frühen Neuzeit. Wissensgeschichte der Architektur. Band III: Vom Mittelalter bis zur Frühen Neuzeit, eds J. Renn, W. Osthues \& H. Schlimme, Edition Open Access: Berlin, pp. 97-334, 2014.

[8] Gerber, A., Metageschichte der Architektur. Ein Lehrbuch für angehende Architekten und Architekturtheoretiker. Transcript: Bielefeld, 2014.

[9] Noell, M., Bewegung in Zeit und Raum. Zum erweiterten Architekturbegriff im frühen 20. Jahrhundert in Raum-Dynamik: Beiträge zu einer Praxis des Raumes, eds F. Hofmann, S. Lazaris \& J. Sennewald, Transcript: Bielefeld, pp. 301-314, 2004.

[10] Minkowski, H., Raum und Zeit. Das Relativitätsprinzip. Eine sammlung von Abhandlungen, eds H.A. Lorentz \& A.M. Einstein, Teubner: Leipzig/Berlin, pp. 5673, 1913.

[11] Moelle, H., Rechnergestützte Planungsprozesse der Entwurfsphasen des Architekten auf Basis semantischer Modelle. Dissertation, Technische Universität München, 2006.

[12] Höfler, C., Form und Zeit: Computerbasiertes Entwerfen in der Architektur. Dissertation, Humboldt-Universität zu Berlin, 2009.

[13] Junge, R., Interoperabilität mit IFC: Entwicklung, Grundlagen, Schema. Vortrag zum BIM Workshop, Bauhaus-Universität Weimar, 6 Nov. 2008.

[14] Wender, K., Das virtuelle Bauwerk als Informationsumgebung für die Planung im Bestand. Dissertation, Bauhaus-Universität Weimar, 2009.

[15] Mies, C.E., Begin with the end in mind: A guide to process transformation. BIM for ICS, eds C. Achamer \& I. Kovacic, Technische Universität Wien, pp. 22-29, 2013. 